\title{
Rational Emotive Behavior Therapy sebagai Alternatif Pemulihan Trauma Bagi Korban Kekerasan dalam Pacaran
}

\author{
Fitri Kurnia Sari \\ Fakultas Psikologi, Universitas Kristen Satya Wacana \\ fitrimenulis@gmail.com \\ Sutarto Wijono \\ Fakultas Psikologi, Universitas Kristen Satya Wacana \\ sutartown@yahoo.com \\ Arianti Ina Restiani Hunga \\ Fakultas Interdisiplin-Pasca Sarjana Studi Pembangunan \\ Universitas Kristen Satya Wacana \\ ina.hunga@uksw.edu
}

\begin{abstract}
One of the effects of violence in courtship is that the victim experiences trauma. The purpose of this literature review is to explain how the REBT psychotherapy approach can be used to recover trauma from victims of dating violence. Through the literature review method, discussions about REBT therapy in the recovery of trauma victims are carried out. Trauma has a negative impact on victims, in this case adolescents because it will affect the decline in thinking, emotional, and behavioral. To overcome trauma, recovery is needed to cure victims of violence in courtship, so that they can live their lives normally again. Factors of thoughts, feelings, and behavior are fundamental to the approach with REBT. These three factors are related to disorders caused by trauma. The conclusion from the discussion shows that Rational Emotive Behavior Therapy can be used to recover trauma from survivors of violence in dating relationships.
\end{abstract}

Keywords : victims; dating violence; trauma recovery; REBT; adolescents

\begin{abstract}
Abstrak
Salah satu dampak dari kejadian kekerasan dalam pacaran adalah korban mengalami trauma. Tujuan review literatur ini adalah memaparkan bagaimana pendekatan psikoterapi REBT dapat digunakan untuk memulihkan trauma pada korban kekerasan dalam pacaran. Melalui metode tinjauan literatur, dilakukan pembahasan tentang terapi REBT dalam pemulihan trauma korban. Trauma memberikan dampak negatif bagi korban, dalam hal ini remaja karena akan memengaruhi penurunan daya pikir, emosional, dan perilaku. Untuk mengatasi trauma perlu dilakukan pemulihan untuk menyembuhkan korban kekerasan dalam pacaran, agar dapat menjalani kehidupan dengan normal kembali. Faktor pikiran,
\end{abstract}


perasaan, dan tingkah laku merupakan hal yang mendasar pada pendekatan dengan REBT. Ketiga faktor tersebut berhubungan dengan gangguan yang ditimbulkan akibat trauma. Kesimpulan dari pembahasan menunjukkan Rational Emotive Behavior Therapy bisa digunakan untuk memulihkan trauma pada penyintas kekerasan dalam hubungan pacaran.

Kata kunci: : korban; kekerasan dalam pacaran; pemulihan trauma; REBT; remaja

\section{Pendahuluan}

Hasil survey yang dilakukan WHO (2013) menyebutkan terdapat peningkatan pada kasus kekerasan terhadap perempuan. Di Amerika Serikat, dengan perbandingan 1 dari 4 perempuan akan menerima kekerasan dari pasangannya (Breiding, Black, \& Ryan, 2008). Efek dari kasus kekerasan tersebut juga akan menambah biaya untuk pemulihan kesehatan mental penyintas di Amerika Serikat (Rivara, 2007).

Kondisi di kawasan Asia Tenggara, dari hasil penelitian World Health Organization (2013) menunjukkan kawasan ini pada posisi tertinggi, dengan prosentase 37,7 \%. Untuk Mediteranian Timur 37\%, dan Afrika 36,6 \%. Menurut survey Thomson Reuters Foundation, Indonesia menempati peringkat ketiga negara terburuk untuk wanita. Peringkat pertama adalah negara India, sedangkan yang kedua negara Arab. Hal itu karena nyaris setiap hari ada kekerasan yang terjadi terhadap perempuan. Survey Thomson dilakukan pada tahun 2012 dengan mengambil 63 negara (Baldwin, 2012).

Komisi Nasional (Komnas) anti kekerasan terhadap perempuan di Indonesia menyebutkan ada 406.178 kasus kekerasan terhadap perempuan. Dari tahun ke tahun data dari Komnas selalu ada peningkatan jumlah kekerasan terhadap perempuan. Sebagai contoh di tahun 2018 terdapat peningkatan sejumlah 14\% yaitu 348.446 kasus dalam CATAHU 2019.

Selanjutnya, hasil temuan melalui data monitoring Legal Resource Center untuk Keadilan Jender dan Hak Asasi Manusia (LRC-KJHAM) dari tahun 2013-2018 ada 2.289 kasus kekerasan terhadap perempuan dengan 4.427 perempuan korban kekerasan. Adapun 50\% nya, 2.454 perempuan adalah korban kekerasan seksual. Artinya, di Jawa Tengah, setiap hari ada 1 sampai 2 
perempuan menjadi korban kekerasan seksual. Kabupaten Wonogiri tercatat sebanyak 20 kasus atau 9,12\%, Kabupaten Salatiga, Kabupaten Pati, dan Kabupaten Semarang terdapat 12 kasus atau 7,10\%, disusul Kabupaten Blora dan Kabupaten Pekalongan sebanyak 10 kasus atau 2,26\%.

Dampak yang ditimbulkan akibat kasus kekerasan dalam pacaran sangat serius. Di antaranya adalah kehamilan yang tidak diinginkan. Dari data WHO (2013) menunjukkan 38\% kehamilan yang tidak diinginkan yang terjadi di dunia setiap tahunnya, sekitar 80 juta kehamilan. Dari 38 persen itu terdiri dari 34 juta kelahiran yang tidak diinginkan, 4 juta mengalami keguguran, dan 42 juta aborsi. Sinaga pada tahun 2010 dalam penelitiannya menyebutkan ada 1 juta kehamilan di luar nikah pada remaja di Indonesia.

Dalam sejarah manusia, baik laki-laki atau perempuan tumbuh dalam dunia yang telah dikontruksikan oleh lingkungan sosial sejak mereka dilahirkan. Kontruksi tersebut tidak dapat dipisahkan dari budaya patriaki yang dianut sebagian besar masyarakat Indonesia, dimana laki-laki dianggap lebih berkuasa dibanding perempuan. Hal tersebut kadang menimbulkan kekerasan terhadap pasangan, baik yang sudah menikah ataupun belum.

Beberapa bentuk kekerasan dalam pacaran dari penelitian Annisa tahun 2012 meliputi kekerasan fisik, kekerasan psikologis, kekerasan seksual, kekerasan ekonomi, dan kekerasan stalking. Jenis kekerasan dalam pacaran mencakup kekerasan terhadap fisik dan juga psikis. Dampak yang muncul berupa kecemasan, kesedihan, rasa malu, depresi, serta kekaburan identitas. Hal itu ada dalam penelitian Marcelina pada tahun 2008. Adapun menurut Ayu, Hakimi dan Hayati (2012) reaksi akibat kekerasan dalam pacaran juga bisa menyebabkan penyintas mengalami susah tidur, takut, tidak percaya pada laki-laki, dan juga sering menangis.

Dari pemaparan di atas, perlu untuk segera dilakukan penanganan psikologis terhadap penyintas kekerasan dalam pacaran. Sedangkan selama ini penanganan kasus kekerasan masih berputar pada hukuman terhadap pelaku kekerasan. Padahal dampak psikologis pada penyintas dapat terjadi dalam selang 
waktu yang lama dan itu akan sangat mengganggu kehidupannya. Adapun salah satu dampak psikologis dari kekerasan dalam pacaran adalah trauma.

Kejadian traumatis merupakan kejadian yang tidak menyenangkan, menyakitkan, dan membuat penyintas / korban menjadi tertekan dan merasa tidak sanggup menjalaninya. Adapun kejadian yang membuat trauma biasanya berupa kecelakaan, bencana alam, kekerasan, pemerkosaan, ataupun kekerasan seksual (Barabaz, 2011).

Dalam suatu kesempatan, Sondang Irene (2003) menyebutkan bahwa pengalaman traumatis dapat membuat penyintas merasa lemah dan tidak sanggup menjalani kehidupannya kembali. Seseorang yang mengalami trauma, menurut penelitian, terdapat bagian pada otaknya menjadi semakin aktif dan tidak terkendali dalam mengatur emosinya (Barabaz, 2011).

Dari kenyataan di atas, maka paper ini akan membahas salah satu bentuk terapi untuk memulihkan trauma, yaitu dengan pendekatan behavior kognitif berupa Rational Emotive Behavior Therapy (REBT). Terapi tersebut berdasarkan teori REBT yang diciptakan oleh psikolog klinis bernama Albert Ellis. Pendekatan Rational-Emotive Behavior Therapy (REBT) ini merupakan pendekatan behavior kognitif yang menekankan pada keterkaitan antara perasaan, tingkah laku dan pikiran. Hal ini berkaitan dengan gangguan yang diakibatkan trauma berupa gangguan emosi, pikiran, dan perilaku. Pada pendekatan Rational Emotive Behaviour Therapy (REBT) ini, penyintas kekerasan dalam pacaran dibantu untuk menemukan pikiran irasional yang terbentuk. Setelah diperoleh pikiran irasional, maka penyintas diajak untuk menumbuhkan pikiran rasionalnya. Adapun pikiran rasional ini sangat berguna untuk menggantikan pikiran irasional. Hal itu sangat bermanfaat untuk mengatasi masalah emosi yang terjadi pada penyintas kekerasan.

\section{Pembahasan}

\section{Reaksi Stres Pasca Trauma}

Dampak dari kekerasan dalam pacaran dapat memengaruhi kondisi fisik maupun psikis remaja. Penyintas kekerasan dalam pacaran biasanya mengalami 
kecemasan, depresi, penurunan self esteem, takut, dan juga gejala somatis, sampai posttraumatic stress disorder (PTSD). Remaja yang mengalami reaksi pasca trauma dapat berlanjut ke PTSD. Oleh karenanya perlu dilakukan penanganan segera untuk memulihkannya.

Reaksi stres pasca trauma merupakan sebuah respon yang terjadi setelah individu terpapar pada sebuah kejadian traumatis atau sekelompok kejadian yang membuat stres. American Psychiatric Association (2013) mendefinisikan kejadian traumatis sebagai kejadian yang berupa pengalaman atau menyaksikan kejadian yang melibatkan kematian, atau ancaman lain terhadap individu, menyaksikan kejadian yang melibatkan kematian yang tidak diinginkan, kerugian, atau ancaman kematian atau cidera yang dialami anggota keluarga atau saudara dekat lainnya.

Reaksi stres pasca trauma yang dialami korban kekerasan pada umumnya memiliki gejala yang serupa dengan simtom-simtom utama dari gangguan stres pasca trauma. Simtom pertama adalah adanya pengalaman kembali kejadian traumatis (Re-experience). Individu biasanya memiliki ingatan tidak menyenangkan (intrusive) dan berulang mengenai kejadian tersebut atau mengalami mimpi buruk. Simtom ini juga dapat menyebabkan individu mengalami flashback dimana ia dapat merasakan dan berperilaku seolah-olah kejadian traumatis sedang terjadi (American Psychiatrist Association, 2013). Individu dapat tiba-tiba merasa sangat terganggu oleh hal-hal yang mengingatkan kejadian traumatis tersebut (Friedman, Keane, \& Resick, 2007).

Simtom kedua adalah menghindari stimulus atau hal-hal yang berkaitan dengan kejadian traumatis (avoidance). Individu umumnya akan dengan sengaja berusaha menghindari pikiran, perasaan, atau percakapan mengenai kejadian traumatis. Simtom ketiga adalah meningkatnya arousal atau reaksi fisiologis secara berlebihan ketika teringat kejadian trauma. Hal tersebut membuat penyintas menjadi terganggu dalam menjalani kegiatan hidupnya sehari-hari.

Kekerasan dalam hubungan pacaran sendiri memiliki berbagai istilah, diantaranya Intimate Patner Violence (IPV), relationship violence, atau dating 
violence (CDC, 2018). Namun hal esensial yang sama di antara semua istilah itu adalah semuanya dilakukan dalam konteks hubungan dekat.

Remaja yang mengalami kekerasan dalam pacaran akan mendapatkan masalah bagi dirinya. Hal itu karena dampak buruk yang dialami dalam kehidupan mereka. Selain dampak dalam hal fisik seperti luka-luka yang terlihat oleh mata, terdapat juga dampak pada kesehatan mental remaja (Callahan, Tolman, \& Saunders, 2003). Korban kekerasan dalam pacaran pada umumnya terjadi pada perempuan. Namun, dalam beberapa kasus dapat terjadi juga pada laki-laki.

Pengalaman traumatis korban KDP tersebut menjadi sangat mendalam bersamaan dengan intensitas kekerasan yang dialami korban serta lama hubungan yang terjalin antara korban dan pelaku KDP. Pengalaman traumatis yang dialami korban akan menjadi semakin sulit untuk disembuhkan ketika korban hanya berjuang seorang diri dalam menghadapi trauma yang dialami. Oleh karena itu diperlukan juga intervensi atau bantuan dari pihak lain untuk membantu memulihkan korban.

Remaja korban kekerasan dalam pacaran yang mengalami trauma akan sulit menjalani kehidupannya sehari-hari. Hal ini disebabkan karena mereka akan mengalami gangguan emosi, penurunan intelektual, serta perilaku. Hal tersebut sangat perlu diperhatikan agar segera dilakukan pemulihan. Bisa dikatakan, individu yang mengalami trauma akan mengalami gangguan pikiran, emosi, dan perilaku.

\section{Kekerasan dalam Pacaran dalam kerangka Teori Ekologi Bronfenbrenner}

Teori ekologi Bronfenbrenner banyak digunakan sebagai acuan dalam penelitian tentang kekerasan. Menurut Banyard (2011), kerangka teori ekologi ini sangat cocok untuk menelaah beberapa fenomena kekerasan yang terjadi. Hal itu karena teori ekologi ini memandang dari empat sistem yang saling berkaitan, yaitu mikrosistem, mesosistem, eksosistem, makrosistem, dan kronosistem. Kronosistem sendiri ditambahkan oleh Bronfenbrenner setelah beberapa tahun.

Bronfenbrenner (1977) menciptakan model teori ekologi menjelaskan bahwa perkembangan seseorang akan dipengaruhi oleh interaksi antar beberapa sistem. Mikrosistem merupakan lapisan terdalam, dimana individu berinteraksi 
dengan lingkungan rumah, tempat kerja ataupun sekolah. Sedangkan mesosistem merupakan relasi dari dua atau lebih mikrosistem, seperti interaksi antara tempat kerja dan rumah. Eksosistem merupakan lapisan berikutnya, dimana ada dampak terhadap individu, seperti lingkungan komunitas, media massa, atau rumah sakit. Sedangkan lapisan makrosistem terdiri dari nilai-nilai budaya pada masyarakat. Kronosistem adalah lapisan terluar yang ditambahkan Bronfenbrenner berisi tentang kejadian-kejadian historis yang dapat memberikan dampak terhadap sistem-sistem pada lapisan sebelumnya.

Foshee (2011) menyebutkan faktor dalam mikrosistem yaitu keluarga dan interaksi didalamnya dapat memberikan dampak pada kekerasan dalam pacaran. Keluarga yang sering terjadi konflik, hubungan antar anggota keluarga yang tidak harmonis, serta pola asuh dari orang tua dapat mendukung peningkatan resiko kekerasan dalam hubungan pacaran. Penelitian Vagi (2013) menyebutkan bahwa kekerasan yang terjadi dalam sebuah keluarga dapat menyebabkan anak terpapar kekerasan yang dapat membuat anak melakukan kekerasan dalam pacaran kedepannya.

Sedangkan pada penelitian Forshee (2010) menyebutkan lingkungan peer grup dapat memengaruhi kekerasan dalam pacaran. Peer grup yang mempunyai perilaku anti sosial, sering melakukan kekerasan, dapat meningkatkan risiko remaja dalam lingkungan peer tersebut juga melakukan kekerasan dalam hubungan pacaran. Di sisi lain menurut Vagi (2013) menjelaskan interaksi antar mikrosistem yang buruk juga dapat memengaruhi seseorang menjadi terbiasa dengan konflik, sehingga ketika dia berinteraksi dengan orang lain akan mempunyai konflik juga.

Begitu juga pada eksosistem, jika pada sebuah komunitas terjadi kekerasan, maka seseorang yang berada dalam sistem itu juga akan terpapar dan dapat meningkatkan kejadian kekerasan dalam pacaran (Vagi, 2013). Sedangkan penelitian Connoly (2010) menjelaskan tentang efek dari berita tentang kekerasan dapat memengaruhi seseorang dalam kekerasan karena terpapar. 


\section{REBT (Rational Emotive Behavior Therapy)}

Kekerasan dalam hubungan pacaran bisa berefek membuat korban menjadi berpikir irasional. Dalam REBT, dilakukan pendekatan untuk mengajak korban kekerasan dalam hubungan pacaran untuk menggantikan pikiran irasionalnya dengan pikiran rasional. Proses penggantian biasa disebut dengan disputing. REBT sendiri diciptakan oleh Dr. Albert Ellis, seorang psikolog pada tahun 1955 (Corey, 1995).

Pendekatan yang akan dilakukan dengan Rational Emotive Behavior Therapy (REBT) merupakan pendekatan behavior kognitif, dimana terdapat keterkaitan antara pikiran (rational), perasaan (emotive), dan tingkah laku (behavior). Menurut Albert Ellis, setiap orang memiliki kemungkinan untuk berpikir irasional yang dapat diperoleh dari dari belajar sosial yang dilakukan. Di sisi lain, seseorang juga dapat belajar kembali agar memeroleh pikiran rasional.

Ellis mengatakan, bahwa pikiran irasional dapat menyebabkan seseorang menjadi terganggu emosinya. Hal itu dapat menjadi masalah bagi kehidupan individu dan menghambat. Individu menjadi salah interpretasi terhadap sebuah kejadian. Selain itu individu juga menjadi salah interpretasi terhadap diri, orang lain, dan juga lingkungan dimana dia tinggal (Frogatt, 2005).

Tiga filosofi dasar penanganan masalah secara rasional yang ditekankan REBT menurut Albert Ellis dalam bukunya (Ellis, 2006) adalah Unconditional Self-Acceptance (penerimaan diri tanpa syarat) yaitu individu mau menerima dan menghargai diri sendiri, Unconditional Other-Acceptance (penerimaan tanpa syarat terhadap orang lain) yaitu individu menerima dan menghargai orang lain, Unconditional Life-Acceptance (penerimaan tanpa syarat terhadap hidup) yaitu individu dapat menerima segala sesuatu yang tidak bisa diubah.

Rosner (2011) dalam penelitiannya mengatakan bahwa pendekatan Rational Emotive Behavior Therapy dapat menangani kondisi emosi dan psikologis individu yang mengalami kekerasan. Sedangkan menurut Sava (2009) dalam penelitiannya mengatakan bahwa seseorang yang mengalami depresi akan merasa dirinya tak berguna, buruk, sehingga hal itu dapat memengaruhi kondisi psikologisnya. Selain itu, hubungan individu tersebut dengan lingkunganpun jadi 
terganggu. Dalam penelitian Matud (2005) menyatakan bahwa salah satu penanganan depresi yang efektif menggunakan pendekatan REBT. Penelitian Anggreiny (2013) menunjukkan bahwa REBT dapat meningkatkan kemampuan mengatasi masalah emosi pada remaja penyintas kekerasan seksual.

Prinsip dasar dari REBT adalah menggantikan pikiran irasional yang muncul akibat peristiwa tertentu dengan pikiran rasional. Hal ini untuk mengatasi gangguan emosi yang muncul. Adapun beberapa cara yang dapat dilakukan untuk disputing pikiran irasional dengan pikiran rasional adalah dengan pekerjaan rumah, saling berargumentasi, dan membuat pernyataan diri yang positif (Frogatt, 2005).

\section{Faktor-faktor yang memengaruhi pemulihan trauma}

Kinchin dan Brown (2001) mengemukakan beberapa faktor yang memengaruhi pemulihan trauma meliputi keyakinan diri, usia, kepribadian, dukungan dari orang yang dekat dengan korban, dukungan dari sekolah, pandangan agama dan budaya, dukungan berkelanjutan dari para profesional, hubungan dengan orang lain, bagaimana munculnya trauma, dan informasi mengenai apa yang telah terjadi. Hal tersebut dimasukkan ke dalam 3 hal yaitu individu / korban, lingkungan, dan peristiwa traumatik.

\section{Tahapan dalam REBT}

Dalam REBT terdapat sebuah model yang relatif sederhana untuk memahami bagaimana aspek pemikiran dapat menciptakan perasaan terganggu, dan bagaimana mengatasi pikiran-pikiran yang menimbulkan gangguan. Adapun tahapannya adalah seperti berikut:

a) Antecedent event (A), yaitu peristiwa yang memicu. Misalnya, kekerasan verbal yang dilakukan seseorang kepada pasangannya dengan mengatakan jika pasangannya adalah orang yang tidak berguna.

b) Belief (B), yaitu keyakinan yang mendasari pandangan seseorang mengenai peristiwa yang dialami. Misalnya, setelah kejadian pada kasus A akan menimbulkan keyakinan pada diri korban, bahwa apa yang dikatakan pacarnya adalah benar yaitu ia tidak berguna. 
c) Emotional dan behavioral consequence (C) adalah konsekuensi perilaku emosi yang ditentukan oleh kepercayaan seseorang tentang peristiwa tersebut. Misalnya, konsekuensi dari contoh kasus A, muncul belief, dan selanjutnya akan memunculkan konsekuensi, korban menjadi rendah diri karena ia tidak berguna.

d) Disputing (D) adalah mendebat keyakinan yang menyebabkan gangguan emosi. Dalam tahap ini, korban dibantu untuk mengembangkan model berpikir baru yang lebih fungsional. Misalnya, korban merasa bahwa ia sebenarnya berguna dan untuk apa merasa rendah diri dan berlarut-larut didalamnya. Korban berupaya bisa menunjukkan kemampuan positifnya.

e) Effective (E) merupakan pandangan rasional efektif dan baru yang diikuti perubahan emosional dan perilaku. Misalnya, korban sekarang lebih bisa menerima diri dan yakin akan kemampuannya dan berguna.

Terapi dalam REBT ini pada intinya merupakan aplikasi dari filosofi ABC ditambah dengan intervensi DE. Terapi REBT ini dapat membantu individu untuk meminimalkan gangguan emosional yang terjadi, menurunkan perilaku yang merusak diri, serta mengarahkan individu ke aktualisasi diri sehingga individu memiliki kehidupan yang bahagia. Dengan kata lain, REBT dapat membantu individu agar lebih rasional dan jelas dalam berpikir, berperasaan, dan berperilaku secara efektif dan efisien untuk mencapai tujuan-tujuan dalam hidupnya. Adapun strategi yang dapat digunakan dalam disputing adalah dengan ceramah, debat, humor, dan kreatifitas. REBT mengutamakan aspek pikiran, namun tidak melupakan aspek perasaan dan tingkah laku.

Keyakinan irasional yang muncul pada diri seseorang biasanya meliputi, tuntutan yang terlalu tinggi terhadap diri sendiri, melebih-lebihkan sesuatu dari kondisi yang sebenarnya, merasa tidak nyaman, serta tidak dapat menerima diri sendiri. 


\section{Penelitian terdahulu mengenai Rational Emotive Behavior Therapy mengenai kekerasan terhadap perempuan}

Penelitian-penelitian sebelumnya tentang REBT tentang kekerasan kepada perempuan pernah dilakukan. Menurut Lestari, dalam penelitiannya pada tahun 2013, intervensi REBT terhadap korban kekerasan dalam rumah tangga dapat mengatasi masalah depresi korban, dengan menggali pikiran rasional untuk mengganti pikiran irasional. Hal itu juga dapat mengurangi gangguan emosi yang dialami korban.

Berikutnya, Hyland, dkk 2013 melakukan penelitian untuk (Hyland, Shevlin, Adamson, \& Boduszek, 2014) menguji prediksi teoritis utama teori terapi perilaku emotif rasional (REBT) dengan menilai peran kepercayaan irasional umum dan trauma-spesifik dalam prediksi respon stres pasca trauma dengan menggunakan sampel 313 pegawai layanan emergency yang mengalami trauma. Hasil pemodelan persamaan struktural menunjukkan bahwa model berbasis REBT memberikan kesesuaian model yang memuaskan dan menjelaskan $89 \%$ varian dalam gejala stres pasca trauma (Lestari, 2013). Prediksi teoretis didukung, dengan hasil yang menunjukkan bahwa irasionalitas tingkat umum secara tidak langsung memengaruhi respons stres pasca trauma melalui serangkaian keyakinan irasional spesifik trauma. Hasil menunjukkan pentingnya kepercayaan irasional dalam memprediksi respons stres pasca trauma.

Hyland dkk pada tahun 2014 juga melakukan penelitian lain. Penelitian yang ia lakukan bersama teman-temannya secara langsung menguji prediksi terpusat dari terapi perilaku emotif rasional (REBT) yang telah menerima sedikit perhatian empiris mengenai keyakinan inti dan menengah dalam pengembangan gejala stres pasca trauma. Model REBT yang konsisten secara teoritis dari gangguan stres pasca trauma (PTSD) diperiksa menggunakan teknik pemodelan persamaan struktural di antara sampel 313 personel militer dan penegak hukum yang mengalami trauma. Hasil: Model REBT dari PTSD memberikan kecocokan. Hasil menunjukkan bahwa keyakinan menuntut (demands) secara tidak langsung memengaruhi berbagai kelompok gejala PTSD melalui seperangkat keyakinan irasional sekunder yang mencakup bencana, toleransi frustrasi rendah, dan 
keyakinan depresiasi. Hasil yang konsisten dengan prediksi teori REBT dan memberikan dukungan empiris yang kuat bahwa variabel kognitif yang dijelaskan oleh teori REBT adalah konstruksi kognitif kritis dalam prediksi gejala PTSD.

Pada penelitian lain, Sudiatmika (2013) melakukan penelitian eksperimen kuasi terhadap 60 responden pelaku kekerasan di Rumah Sakit Dr. H. Marzoeki Mahdi Bogor. Hasil penelitiannya menunjukkan bahwa terjadi penurunan gejala perilaku kekerasan setelah pemberian CBT dan REBT. Pemberian CBT dan REBT juga dapat meningkatkan kemampuan kognitif, afektif, dan perilaku klien. Dalam terapi keperawatan, terapi CBT dan REBT juga dianjurkan untuk menangani perilaku kekerasan dan halusinasi pada klien.

Dari hasil-hasil penelitian yang sudah dipaparkan di atas, menunjukkan bahwa REBT sebagai sebuah treatmen dapat mengatasi depresi korban kekerasan, mengatasi gangguan emosi, meningkatkan pola pikir rasional, serta menurunkan gejala perilaku kekerasan.

\section{Kesimpulan dan Saran}

Dari review literatur di atas, dapat ditarik kesimpulan bahwa fenomena kekerasan dalam pacaran yang terjadi perlu segera ditangani. Trauma yang terjadi pada korban kekerasan dalam pacaran jika tidak segera ditangani dengan cepat dan cara yang tepat, maka akan merugikan korban yang masih remaja. Padahal remaja merupakan generasi penerus bangsa, cerminan bangsa.

Korban kekerasan dalam hubungan pacaran akan mengalami gangguan pikiran, emosi, dan perilaku akibat trauma pada diri korban. Salah satu alternatif untuk mengatasi gangguan-gangguan tersebut adalah dengan pendekatan Rational Emotive Behavioral Therapy (REBT). Hal tersebut karena konsep Rational Emotive Behavioral Therapy sendiri dari penelitian sebelumnya adalah dapat meningkatkan kemampuan pikiran, perasaan, dan perilaku korban kekerasan dalam pacaran. REBT sendiri berfokus untuk mengubah keyakinan irasional pada diri seseorang, dan menggantikannya dengan keyakinan rasional.

Rosner (2011) dalam penelitiannya menyebutkan bahwa dampak dari kekerasan meliputi kondisi psikologis dan emosi korban dapat ditangani dengan 
dengan pendekatan Rational Emotive Behaviour Therapy. Sedangkan pada penelitian Sava tahun 2009 menyatakan depresi bisa membuat seseorang mempunyai pernyataan yang buruk pada dirinya. Hal itu memengaruhi psikis dan mengganggu hubungan dengan lingkungannya. Pendekatan REBT mereduksi pola pikir dan pernyataan diri yang negatif untuk mengembangkan pikiran rasional.

Penelitian yang akan datang, disarankan menggunakan literatur yang lebih banyak, seperti jurnal-jurnal terkait dengan penelitian. Hal itu akan lebih mempermudah untuk mengupas lebih dalam tentang psikoterapi dengan pendekatan REBT terhadap korban kekerasan dalam hubungan pacaran.

\section{DAFTAR PUSTAKA}

American Psychiatric Association. (2013). Diagnostic and statistical manual of mental disorder (5th ed.) Washington, D.C.

Annisa, R. (2012). Kekerasan dalam pacaran (dating violence). Diambil dari http:rifkaanisa.blogdetik.com/2012/10/23/kekerasan-dalam-pacaran-datingviolence/comment-page- $1 /$.

Ayu, M. S., Hakimi, M., \& Hayati, E.N., (2012). Kekerasan dalam pacaran dan kecemasan remaja putri di kabupaten purworejo. KES MAS, 6, 1-47.

Baldwin, K. (2012). Factbox: The worst and best G20 countries for women. Thomson Reuters Foundation. Retrieved from http://www.trust.org/item/20120613010100sk134/?source=spotlight

Barabasz., Areed., \& Watkins. (2011). Single session manualized ego state therapy for combat stress injury, post traumatic stress disorder, part 1: The Teory, International Journal of clinical and experimental hypnosis, 59, 379391.

Breiding, M. J., Black, M. C., \& Ryan, G. W. (2008). Prevalence and risk factors of intimate partner violence in eighteen U.S. states/territories in 2005. American Journal of Preventative Medicine, 34(2), 112-118. doi: 10.1016/j.amepre.2007.10.00

Bronfenbrenner, U. (1995). Developmental ecology through space and time: A future perspective. In P. Moen, G. H. Elder, Jr., \& K. Luscher (Eds.), Examining lives in context: Perspectives on the ecology of human development (hal. 619-647). Washington, DC: American Psychological Association. 
Corey., (2009). Teori dan Praktek Konseling \& Terapi, Bandung: Refika Aditama.

Creswell, J. W., (2010). Research Design Pendekatan Kualitatif, Kuantitatif, dan Mixed.Yogyakarta : Pustaka Pelajar.

Ellis, A., (2006). Terapi R.E.B. Agar Hidup Bebas Derita. Yogyakarta: B-First.

Ellis, A., \& Dryden, W. (2007). The practice of rational emotive behavior therapy. New York: Springer

Froggatt, W., (2005). A Brief Introduction To Rational Emotive Behaviour Therapy. Journal of Rational-Emotive and Cognitive Behaviour Therapy, 3 (1): 1-15.

Hatta, K., (2016). Trauma dan Pemulihannya.Aceh: Dakwah Ar-Raniry Press.

Hyland, P., Shevlin, P., Adamson, G., \& Boduszek. (2014). The organization of Irrational Beliefs in Posttraumatic Stress Symptomology: Testing the Predictions of REBT Theory using Structural Equation Modelling. Journal of Clinical Psychology, 70(1), 48-59.

Hyland, P., Shevlin, P., Adamson, G., \& Boduszek. (2015). Irrational Beliefs in Posttraumatic Stress Responses: A Rational Emotive Behavior Therapy Approach. Journal of Loss and Trauma, 20, 171-188.

Lestari, H. S. (2013). Rational emotive behaviour therapy (REBT) untuk menangani gangguan depresi. Thesis, Universitas Muhammadiyah Malang.

Marcelina, L., (2008). Dampak psikologis remaja yang pernah mengalami kekerasan seksual. Skripsi yang tidak dipublikasikan, Universitas Katolik Soegijapranata, Semarang.

Martin, G., \& Pear, J. (2015). Modifikasi perilaku (ed.10). Yogyakarta: Pustaka Pelajar.

Matud, M. P. (2005). The psychological impact of domestic violence on spanish women. Journal of Applied Social Psychology, 35(11), 2310-2322.

Mental Health Channel., (2004). Posttraumatic Stress Dissorder (PTSD), http://www.ncptsd.va.gov/facts/disasters/fs_rescue_workers. html, diakses 04 Mei 2005a

Nurhewati, S., (2013). Perbincangan di Komnas Perempuan tanggal 29 Januari 2013. 
Oemarjoedi, A. K. (2003). Pendekatan cognitive behavior dalam psikoterapi. Jakarta: Penerbit Kreativ Media.

Putri., (2016). Paradoks Cinta: Antara Pengorbanan dan Perpisahan (Kebertahanan Perempuan Korban Kekerasan dalam Perspektif Kelekatan Bowlby). Thesis, Universitas Kristen Satya Wacana, Salatiga.

Safaria, T., \& Saputra, N. (2012). Manajemen Emosi (ed.2). Jakarta: Bumi Aksara.

Safitri, W.A., (2013). Dampak Kekerasan Dalam Berpacaran. Artikel Ilmiah Hasil Penelitian Mahasiswa Unej. I (1): 1-6.

Santrock, J. W. (2013). Life span development. New York: The McGraw-Hill Companies

Sidabutar, Sondang Irene E dkk., (2003). Pemulihan Psikososial Berbasis Komunitas, Kontras dan Yayasan Pulih (Pusat Pencegahan dan Penanganan Trauma Psikologis)

Sinaga, T. (2010). Perilaku remaja terhadap seksual pranikah (Master's Thesis). Universitas Sumatera Utara, Medan.

Sudiatmika, I., Keliat, B., \& Wardani, I. Y. (2013). Efektivitas cognitive behaviour therapy dan rational emotive behaviour therapy terhadap gejala dan kemampuan mengontrol emosi pada klien perilaku kekerasan. Jurnal Keperawatan Jiwa, 1 (1), 1-10.

Susilowati., (2016). Antara Cinta dan Luka: Kajian Psikologi Transpersonal Terhadap Keputusan Berpisah pada Perempuan Korban Kekerasan Dalam Berpacaran. Thesis, Universitas Kristen Satya Wacana, Salatiga.

Talise., (2016). Kebertahanan Perempuan Korban Kekerasan dalam Pacaran (Kajian Psikoanalisa). Thesis, Universitas Kristen Satya Wacana, Salatiga.

World Health Organization. (2013a). Global and regional estimates of violence againts women: Prevalence and health effects of intimate partner violence and non-partner sexual violence. Retrieved from http://www.who.int/reproductivehealth/publications/violence/97892415646 25/en/

World Health Organization. (2013b). Unintended pregnancy: Toward understanding the issues and addressing the need gaps. Geneva: Department of Reproductive Health and Research. 